\title{
Más allá de lo étnico: procesos identitarios entre reivindicación y prácticas tradicionales
}

\author{
Beyond the ethnic: identity processes between vindication and traditional practices
}

\author{
Elvira Maritza Andino \\ Directora Departamento de Antropología \\ Facultad de Humanidades y Ciencias Jurídicas \\ UNAN-Managua. Nicaragua. \\ https://orcid.org/0000-0002-5560-5141 \\ Correo: maritzaapicado@hotmail.com
}

Recibido: 10-11-2017

Aceptado: 20-11-2017

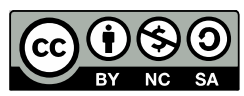

\section{Resumen}

El escrito presenta reflexiones sobre la autoconciencia étnica: identidad de los pueblos originarios, referido a las regiones Pacífico y Centro-Norte de Nicaragua. La hipótesis que se ubica en la antropología nicaragüense tiene como base, que las poblaciones originarias fueron casi exterminadas por la conquista española, sin embargo los elementos de identidad se reconfiguraron como es observable a partir de las manifestaciones actuales. La exposición en el texto, refiere al análisis de la autoconciencia más allá de la superficie de la modernidad, y la negación a la identidad originaria. Desde la antropología se impulsa al reconocimiento de la identidad original en los pueblos actuales, manifestados en sus prácticas culturales, y estructuras sociales.

En el artículo se analiza el significado de la autoconciencia étnica en los pueblos originarios, desde la semilla de sus prácticas arraigadas en su inconsciente colectivo. Partir del origen ancestral, para comprender desde la lógica de identidad, la conciencia étnica, vinculada a las prácticas culturales actuales. Por último se dedican líneas de reflexión sobre las prácticas sociales y culturales, manifestadas en tradiciones y costumbres como formas de conservación de la identidad de las poblaciones.

Palabras claves: Auto conciencia étnica, etnia, pueblos originarios, origen ancestral, identidad cultural.

\section{Abstract}

This paper presents reflections on ethnic self-consciousness: identity of indigenous peoples, referred to the Pacific and Central-North regions of Nicaragua. The theory that is located in Nicaraguan anthropology is based on the fact that the original populations were almost exterminated by the Spanish conquest, however the elements of identity were reconfigured as is observable from the current manifestations. The exposition in the text refers to the analysis of self-consciousness beyond the surface of modernity, and the denial of the original identity. Anthropology drives to the recognition of the original identity in the current people, manifested in their cultural practices, and social structures.

This article analyzes the meaning of ethnic self-consciousness in native people, from the seeds of their practice rooted in their collective unconscious. Starting from their ancestral origins, to understand from the logic of identity, the ethnic conscience, linked to current cultural practices. Finally, there are lines of reflection on social and cultural practices, manifested in traditions and customs as ways of preserving the identity of populations.

Keywords: Ethnic self-awareness, ethnicity, native peoples, ancestral origin, cultural identity 


\section{Componentes culturales en la identidad de los pueblos originarios}

Para analizar el significado de la autoconciencia étnica en los pueblos originarios de las regiones Pacífico y Centro-Norte de Nicaragua, es ineludible tomar en cuenta los valiosos componentes culturales que precisan la existencia y el reconocimiento de las familias originarias a partir del origen ancestral, según Grimson, "un punto de partida necesario es diferenciar las categoría de pertenencia por una parte, y las tramas de prácticas y significados por la otra" (Grimson, 2011, pág. 139).

La categoría de pertenencia se analiza más allá del apego a un territorio, también construye identidad que se articula a las prácticas y costumbres esenciales, que dan significado al mundo de las personas. Grimson (2011), aporta que los pueblos originarios, construyen identidad en un sentido complejo de tramas o bien esferas de prácticas con significantes sustanciales.

En Nicaragua, más allá de la auto identificación con un pueblo originario, existen un sin número de prácticas cotidianas que se comprenden a partir de elementos ancestrales. Por un lado existen quienes se identifican con un pueblo indígena, es decir, tienen un sentido de pertenencia, y también un número considerable de personas que ponen en prácticas saberes de conexión ancestral sin reconocerse en sí mismos indígenas.

Así como, otros elementos que se manifiestan y los identifican como; tradiciones, costumbres, las formas de organización, la vida comunitaria, la transmisión de generación en generación de los valores espirituales resguardados en las prácticas tradicionales de las poblaciones.

Por supuesto existen otros elementos observables entre lo que podemos mencionar, como significantes de un pueblo originario. Por ejemplo, la tenencia de la tierra es una referencia importante, así como el conocimiento tradicional en las formas de producción, los valores de la educación en las familias, como es el cuido del legado de los padres a los hijos. El conocimiento sobre los recursos naturales, las prácticas en relación con la medicina natural para solucionar situaciones de salud en las comunidades. Todo ello ha significado formas de conservación de los pueblos originarios.
Mapa No.1: Pueblos indigenas y afrodescendientes en Nicaragua

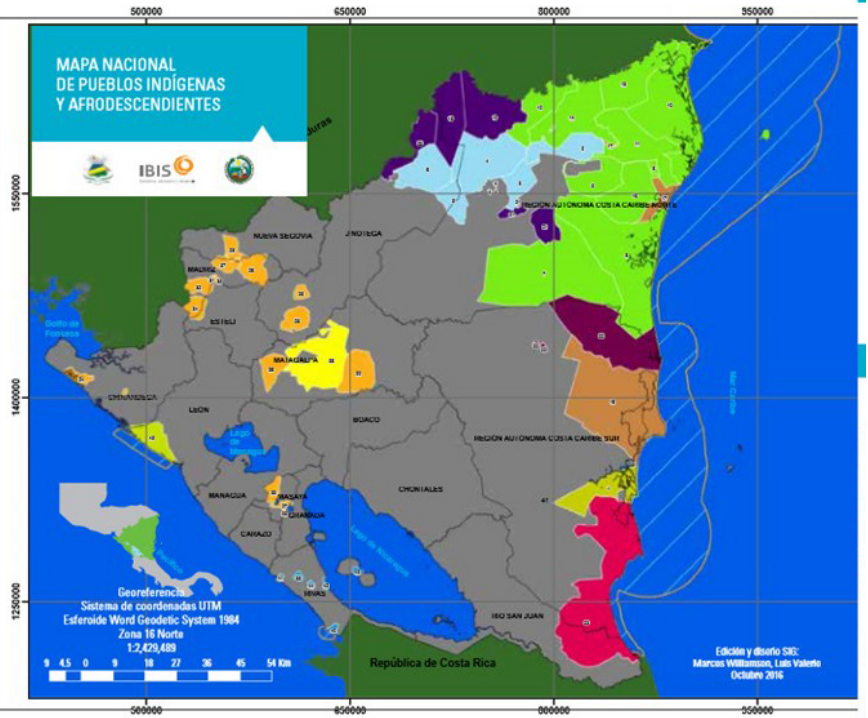

Mapa de los pueblos indígenas, uso y manejo de los recursos.

Fuente: Pueblos originarios y afrodescendientes de Nicaragua: etnografía, ecosistemas naturales y áreas protegidas (UICN, URACCAN, \& APRODIN, 2016)
La ilustración anterior da muestra de la distribución espacial de los actuales pueblos que se adscriben a una descendencia originaria. Es importante destacar que los procesos históricos de la zona del Pacifico no fue similar que la del Caribe. Danilo Salamanca sugiere que "entonces observar, que la línea divisoria que atraviesa el territorio de la actual Nicaragua, de cuyas consecuencias políticas se internan en la historia y en la vida actual de este (...) es en realidad parte de una frontera ancestral que se prolonga hacia el Norte y hacia el Sur y separa a Mesoamérica en su conjunto de las culturas indígenas de la zona intermedia y del Sur del continente (Salamanca, 2012).

Por tanto, indica Salamanca (2012), hablamos que los procesos del territorio han sido vividos por la población de forma diferente. Así en el Pacífico, la colonia española casi extermino a los pueblos originarios, 
en la Costa Caribe, los ingleses junto a sus aliados, encontraron la forma de explotar y negociar con los pueblos autóctonos aprovechando sus recursos y fuerza, pero permitiéndoles vivir bajo sus particularidades culturales.

No obstante, en el Pacífico, estos pueblos tuvieron que someterse al dominio, cultural, lingüístico, político y eso altero el orden original de la población. Aunque como se ha expresado existe una lucha por encontrar esa reivindicación cultural. Generando el actual reconocimiento de los pueblos del Pacífico, Centro y Norte, como se aprecia en la ilustración.

iNosotros si Existimos! Somos más de 333,000 hombres y mujeres Chorotegas, Cacaoperas/ Matagalpas, Xiu/Sutiabas y Nahoas. En nuestras mentes y corazones arde el espíritu de nuestros ancestros: de Diriangén, Nicarao, Sasle, Adiact, Agateyte, Yaguare, Nacacheri, Tenderí y Mosunse. Conservamos el sendero de nuestras abuelas y abuelos que nos enseñaron que somos parte de toda la creación que es la fuente de la vida. Aprendimos que cuidar nuestra madre tierra debe ser una vivencia diaria-igual como cuidarnos nosotros mismos. (APRODIN, 2012)

La lucha por el reconocimiento de los pueblos originarios, es una tarea incesante. Reafirmados posteriormente en el Convenio 169 de la OIT (1989) entrada en vigor el 5 de septiembre de 1991. La Declaración de la ONU sobre derechos de los pueblos indígenas adoptado por la Asamblea General de la ONU en 2007. En el convenio 169 de la OIT, se enfatiza que la conciencia de su identidad indígena o tribal deberá considerarse un criterio fundamental para determinar los grupos a los que se aplican las disposiciones del presente Convenio.
Este marco legal internacional que respalda a los pueblos que se auto determinan originarios, ha tenido un

Cuadro 2: Información básica de los territorios de los pueblos del pacifico y centro norte de Nicaragua,

\begin{tabular}{|c|c|c|c|c|c|}
\hline $\mathbf{N}^{0}$ & $\begin{array}{l}\text { Ascendencias/Pue- } \\
\text { blo Indigenas }\end{array}$ & $\begin{array}{l}\text { Depar- } \\
\text { tamento }\end{array}$ & Municipio & $\begin{array}{l}\text { Re- } \\
\text { gión }\end{array}$ & $\begin{array}{l}\text { Pobla- } \\
\text { ción }\end{array}$ \\
\hline \multicolumn{4}{|c|}{ Ascendencia Nahoa } & \multirow{16}{*}{$\frac{\text { 은 }}{\text { 늠 }}$} & \\
\hline 1 & Ostional & \multirow{6}{*}{ Rivas } & $\begin{array}{l}\text { San Juan del } \\
\text { Sur }\end{array}$ & & \multirow{6}{*}{$\begin{array}{l}20,000 \\
\text { habitan- } \\
\text { tes }\end{array}$} \\
\hline 2 & $\begin{array}{l}\text { San Jorge Nicarao- } \\
\text { cali }\end{array}$ & & San Jorge & & \\
\hline 3 & Salinas de Nagualapa & & Tola & & \\
\hline 4 & Veracruz del Zapotal & & Rivas & & \\
\hline 5 & Nancimí & & Tola & & \\
\hline 6 & $\begin{array}{l}\text { Urbaite-Las pilas y } \\
\text { sus caseríos }\end{array}$ & & Altagracia & & \\
\hline \multicolumn{4}{|c|}{ Ascendencia Chorotega del Pacífico } & & \\
\hline \multirow{2}{*}{7} & \multirow{2}{*}{ Monimbó } & \multirow{4}{*}{ Masaya } & Masaya & & \multirow{4}{*}{$\begin{array}{l}68,000 \\
\text { habitan- } \\
\text { tes }\end{array}$} \\
\hline & & & La Concepción & & \\
\hline 8 & San Juan de Oriente & & $\begin{array}{l}\text { San Juan de } \\
\text { Oriente }\end{array}$ & & \\
\hline 9 & Nindirí & & Nindirí & & \\
\hline \multicolumn{4}{|c|}{ Ascendencia Xiu } & & \\
\hline 10 & Sutiaba & León & Sutiaba & & $\begin{array}{l}49,000 \\
\text { habitan- } \\
\text { tes }\end{array}$ \\
\hline \multicolumn{4}{|c|}{ Ascendencia Chorotega de Occidente } & & \\
\hline 11 & El Viejo & $\begin{array}{l}\text { Chinan- } \\
\text { dega }\end{array}$ & El viejo & & $\begin{array}{l}5000 \text { ha- } \\
\text { bitantes }\end{array}$ \\
\hline
\end{tabular}

N. ETNOGRAFAA DE LOS PUEBTOS ORIGINARIOS Y AFRODESCENDIENTES |4.1. Geomortologia de Nicaragua
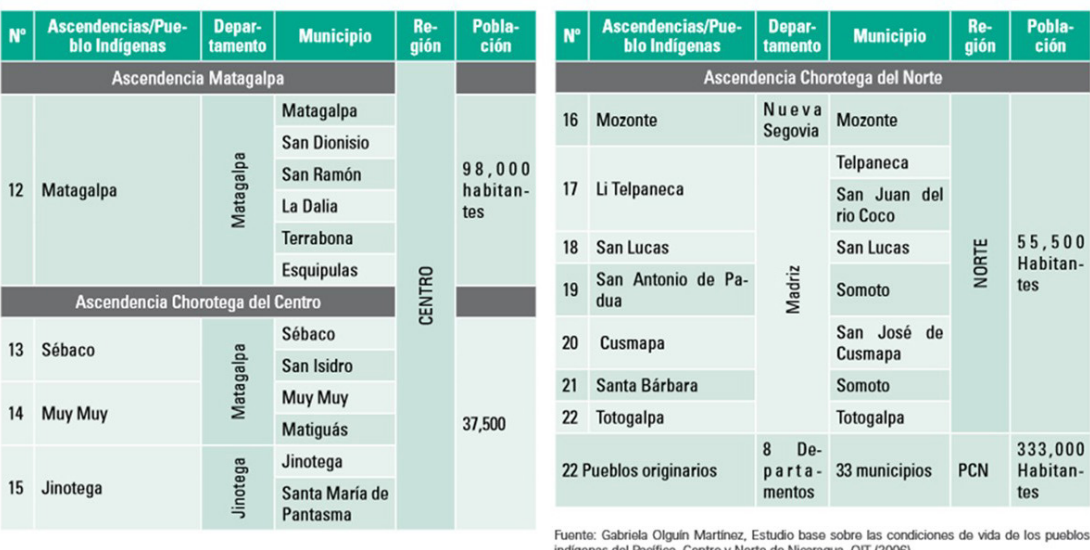

Fuente: Gabriela Olguin Martinez, Estudio base sobre las condicion
indigonas del Padfico, Contro y Norte de Nicaragua, OrT (2006).

Cuadro de distribución de los pueblos y sus características.

Fuente: Pueblos originarios y afrodescendientes de Nicaragua: etnografía, ecosistemas naturales y áreas protegidas (UICN, URACCAN, \& APRODIN, 2016) 
impacto considerado sustancial en los país que lo han adoptado y ratificado. Sin embargo, la realidad local en algunos países del mundo es distinta, no existe un reconocimiento y respaldo como tal, muy por el contrario ha existido una extirpación.

La autoconciencia está ligada a un territorio, lengua, costumbre común, tradiciones y vinculación con un pueblo originario. En el Arto. 2. Del convenio 169 de la OIT dicta que "Los gobiernos deberán asumir la responsabilidad de desarrollar, con la participación de los pueblos interesados, una acción coordinada y sistemática con miras a proteger los derechos de esos pueblos y a garantizar el respeto de su integridad." (Organización Internacional del Trabajo (OIT), 1989)

Parte de estos esfuerzos de reconocer el convenio lo ha hecho Nicaragua. Sus trabajos se reflejan en los grupos autodenominados originarios o indígenas. En el trabajo que se realizó sobre los pueblos indígenas del Pacifico, Centro y Norte de Nicaragua, se destaca un cuadro de datos importante de los grupos actualmente en reconocimiento.

Se reconoce el vínculo ancestral de los actuales pueblos con su ascendencia ancestral u original. En tiempos precolombinos los pueblos Chorotega, Nicarao y los Maribios o Sutiava eran pueblos que habitaban en un corredor rupestre que se extendía desde el actual Golfo de Nicoya hasta el Golfo de Fonseca, junto a la costa de los Lagos y al pie de los volcanes, debido a la abundancia del agua y de suelos abonados por la ceniza volcánica.

Los Chontal-Matagalpa habitaron en el Centro y Norte de Nicaragua constituyendo un mismo grupo. Se les vincula a grupos provenientes del norte y sur del continente. Los Chontales que poblaban el istmo de Rivas fueron desplazados por los Chorotegas en el siglo XI. (UICN, URACCAN, \& APRODIN, 2016)

\section{Cultura material y espiritual de origen ancestral}

Los pueblos en la actualidad en Nicaragua están constituidos bajo un entramado de prácticas culturales con arraigo ancestral, lo que conecta un pueblo a un pasado histórico o un linaje cultural. Posterior a la
Revolución Sandinista, en 1979, existió un proceso de integración nacional, que dio lugar por primera vez de reconocer a los pueblos originarios o tribales, entre esos hallazgos se encuentra la Declaratoria de la Ley 28 de Autonomía en el Caribe.

Por tanto, se ha empleado desde entonces la necesidad de dar el lugar a los pueblos con conexión cultural ancestral y se ha establecidos mecanismo políticos para la construcción de la patria de todos, que está condicionada al reconocimiento de los pueblos originarios a partir de sus tradiciones y costumbres a partir de su cultura espiritual y material.

Lo espiritual y material que se vuelven aspectos esenciales en la cultura de un pueblo para su auto reconocimiento. O bien para determinar características que le den lugar como pueblo de descendencia ancestral. Ante esto, es necesario analizar la reflexión de lo material y espiritual a partir de la propuesta de Jesús Guanche (1983). El antropólogo cubano indica que la cultura espiritual es:

la expresión de los valores creados por las diversas formas de la conciencia social, y por las demás formas de organización y comunicación humana. Estos valores o bienes culturales son la política, el derecho, la moral, la ciencia, el arte la religión, y la filosofía, así como las organizaciones sociales, familiares e interpersonales. (Guanche, 1983)

Por supuesto, la realidad nacional nos indica que los pueblos mantienen un arraigo cultural a su sistema de creencias, que como podemos inferir, es quizás una de las áreas más evidente de esta conexión de la cultura espiritual ancestral. Sin embargo, también existe apego a la cultura espiritual a través de los elementos simbólicos de los conectores lingüísticos populares, o bien a como las personas le llaman cotidianamente a los utensilios domésticos, por ejemplo los comales, o nombre de plantas como el jocote, entre otros.

Existen elementos de la cultura ancestral que se conecta directamente con esta población actual, que aunque existe quizás un rechazo a ese vínculo, en las prácticas usualmente se percibe esa estrecha conexión. Además a los saberes se vinculan elementos que se crean o recrean de la cultura y que son observables, es decir, son tangibles. 
Por lo que se vuelve necesario la definición que realiza el mismo autor a la cultura material, sugiriendo que es "el conjunto de valores tangibles que ha creado la sociedad en su desarrollo y evolución histórica. Entre la cultura material se destacan; la alimentación, la vivienda, el vestir, el transporte, instrumentos de trabajo, del medio natural y las ocupaciones económicas" (Guanche, 1983).

La primera supone: la expresión de los valores intelectuales, tales como la ciencia, el derecho, la moral, la política, entre otros y la segunda es el conjunto de valores tangibles, producidas por el ser humano en su colectivo.

Por consiguiente analizar la cultura de los pueblos para su auto identificación o reconocimiento, conjuga ambos aspectos de la cultura, ya sea espiritual o material. Además implica darle sentido a la vida social de las personas en sus espacios, en sus mundos.

Por ende lo material y espiritual que son realidades categóricas en Nicaragua se asocia al inconsciente colectivo del historiador Aldo Díaz Lacayo (2007), quien enfatiza en el análisis de la cultura actual relacionada con las formas de manifestación originaria. Argumenta que "los pueblos entran a la historia cuando logran superar su prehistoria”. (Lacayo, 2007)

Es entonces el reconocimiento y las prácticas de las manifestaciones culturales actuales, las que marcan el camino hacia la identidad de los pueblos originarios, de acuerdo a investigaciones realizadas en grado y posgrado en el marco de la línea de investigación de Patrimonio Cultural, se ha evidenciado que las familias tienen apego a prácticas que enmarcan su reconocimiento al arraigo ancestral. (Departamento de Antropología , 2017)

El origen ancestral se asocia con la autoconciencia étnica y las reflexiones del origen hereditario permitiendo exteriorizar el aprendizaje del etnos en palabra de Jesús Guanche, es "la condición de la existencia histórica de la comunidad, nos permite detectar las formas primarias del etnos o etnogénesis." (1983)

La autonciencia étnica es otra condición que responde a otro proceso histórico social de evolución. Los etnos más antiguos son las tribus, que se caracterizan desde el punto de vista general, para el estudio de la comunidad primitiva en cuanto a la génesis de la autoconciencia étnica."(íbidem:27)

La modalidad distingue también a una comunidad étnica de otra. Por este término entendemos las condiciones comunes de los individuos pertenecientes a determinados etnos para percibir y asimilar distintos fenómenos naturales y sociales, así como las reacciones conductuales ante una $\mathrm{u}$ otra circunstancias personal, familiar o social.

En la formación de la modalidad psíquica de las personas que constituyen los etnos, desempeñan cierto papel los tipos prevalecientes de temperamento, que revelan su relación con los caracteres antropológicos y proporcionan combinaciones diferentes en las distintas comunidades étnicas. La modalidad psíquica de éstos está condicionada por la características de la vida material, la educación, la concepción del mundo es decir, por la cultura de cada pueblo. (Guanche, 1983, pág. 31)

Lo anterior se conecta a una realidad concreta en cada pueblo, la misma podrá ser percibida en la conciencia, y quizás algunas otras manifestaciones tendrán un manejo quizás más sutil dentro de la cultura. Por sutil, indicamos que no es notablemente detectada o percibida por la población, por tanto esta en un nivel de etnos inconsciente. Esa inconsciencia en el campo cultural, conecta con la autoconciencia étnica. La autoconciencia étnica se origina bajo la influencia de la comunidad de lengua, de territorio, de hábitos y costumbres comunes, tradiciones culturales y la noción de cierta comunidad de origen.

En Nicaragua una reinterpretación, el inconsciente colectivo de Aldo Díaz Lacayo encamina a dotar al nicaragüense de una explicación de su identidad, la que permanentemente se metamorfosea y escapa por los intersticios de los escasos escritos que abordan el tema.

De manera, que esta reinterpretación no es otra cosa que un escalón más en la construcción, vía la reflexión, de la identidad nicaragüense. ¿Y por qué no, del centroamericano y latinoamericano?

El esfuerzo va encaminado, nada más y nada menos, que a explicar por qué el nicaragüense es como es, porque pareciera que nunca logra la unificación entre las ideas y las acciones, entre teoría y praxis. Esto tam- 
bién es lo que intenta hacer Pablo Antonio Cuadra, sólo que con una visión bifurcada. Es decir, el nicaragüense mestizo, descendiente más de indio que de español, es taimado, mentiroso, picado, vivo, etcétera, mientras que los menos indios y más españoles, lo contrario. De allí la visión dual que expresa PAC. Es decir, el nica parece ser permanentemente dos al mismo tiempo. Existen varios antecedentes en esta dirección. (Lacayo, 2007)

En Nicaragua, se reflejan expresiones culturales que bien podría semejarse a la dinámica del Güegüense y su burla a los españoles. El nicaragüense trae consigo una identidad étnica que se manifiesta en sus prácticas como en la astucia del mismo personaje del Güegüense, pero además existe esa negación quizás un poco solapada.

Por su lado Bonfil Batalla indicaba el origen ancestral de los pueblos actuales se encuentra en sus prácticas culturales, las cuales han sido negadas por siglos, pos coloniales (Batalla, 1990). Lo que llama como cultura negada Bonfil Batalla, su propuesta es una invitación, no a iniciar una confrontación ciega con todo lo producido por Occidente, ni a acrecentar y radicalizar el conflicto entre indios y no indios, tampoco a retornar al pasado, sino a explicitar lo que, a través de la resistencia, la innovación y la apropiación, queda en cada mexicano del México profundo, o lo que para nosotros sería el nicaragüense profundo. (Ruiz, 2013)

\section{Tradiciones, costumbres y formas de conservación}

En la antropología nicaragüense, y particularmente en la experiencia de investigación desarrollada en la carrera de Antropología Social de la UNAN-Managua, se localizan investigaciones de grado y posgrado que aportan al análisis antropológico, desde distintas énfasis; económico, social, lingüísticas, sistemas de creencias, educativo, entre otros. En ellas se evidencia, las manifestaciones culturales de los pueblos: una identidad sumergida en las complejas redes de la negación cultural. Detectándose la necesidad por re-encontrase con su pasado reciente y con sus linajes culturales étnicos.

Sin embargo, queda la pregunta abierta ¿Qué hemos encontrados sobre los elementos originarios en las familias y que significado le damos a sus expresiones a partir de sus costumbres y tradiciones?
Ciertamente como investigadores debemos encontrar esos espacios de reflexión, en el que seamos promotores de ese reconocimiento de los pueblos desde sus propias practicas ancestrales. En investigaciones de posgrados se han evidenciado algunos hallazgos encontrados en la observación en El Viejo, Chinandega, que demuestran la existencia de prácticas que se encuentran en nivel no superficial de la cultura de las personas (Andino, 1999). Los pueblos originarios del Pacífico, Centro y Norte del país representan su etnos con una conexión cultural individual y colectiva. Existe presencia de tradiciones que se expresan en la cultura espiritual a través de la música, que logran subsistir ante la modernidad, conectan con sus raíces ancestrales, muestra una mezcla de espiritualismo y cultura material, que trasciende lo cotidiano.

Los ancestros míticos son, por lo general los pueblos indígenas precolombinos: ese "sujeto colectivo" del cual dicen ser descendiente los miembros de las actuales comunidades indígenas latinoamericanas, aun cuando ellos no sean capaces de retrasar empíricamente los lazos de filiación que les unen presuntamente a él. Los indígenas, en cambio, sí son capaces de retrasar los eslabones genealógicos que les unen a sus ancestros empíricos, identificando en cada genealogía pasada el o los parientes que les unen a ellos. (Idiáquez, 1998, págs. 234, 235)

Para los grupos originarios del Pacífico, Centro y Norte, la familia es la primera base de reconocimiento de legitimidad ancestral. A través de sus ancestros se auto reconocen y reproducen los saberes transmitidos por medio de la relación directa entre los parientes generacionales, que se desarrollan en prácticas culturales concretas.

Ante lo anterior, resulta necesario indicar que existen pueblos que entran en conocimiento de su propio etnos, y otros que son motivados en su devenir histórico. Esta experiencia, que no es exclusiva de Nicaragua, se logra apreciar en otros espacios y contextos de Latinoamérica.

Se retoma la experiencia de Isabel Rauber (1992), una investigadora de origen argentino, que recoge testimonios de lideresas indígenas y refleja los procesos de conciencia étnicas que son motivadas, por las prácticas sociales de las informantes. Relata lo siguiente: 
Mi abuelo era trabajador de haciendas y vivía en la comunidad. Siempre estamos vinculados, íbamos muy seguido. Pero mi etapa de infancia más bien crece en la ciudad, donde los otros niños siempre me marginan. Mi papá era albañil y me estaba criando con otra ropa, me había empezado a poner ropa de mestiza de la ciudad influenciado por la señora que ahí comisionaba. Mi abuelo es el que se opone cuando yo tenía dos o tres años, por la experiencia de unos vecinos que tenían una hija muy bonita que se había puesto la ropa mestiza y luego frente al público negaba siempre a sus padres, porque no quería que nadie supiera nada. Decía que esos no eran sus padres y que ella no era su hija. Le dio vergüenza ser india. A su propio padre lo tenía como peón de la casa.

Mi abuelo quería me vistieran como india. Él decía que si me crecen como india, por lo menos ante el público no me avergonzaría de decir: es mi abuelo o, es mi padre... si mi papá decidía crecerme como mestiza, le dijo que el primer golpe lo iba a recibir él mismo, porque es posible que después ya no lo reconozca en público...que si negábamos a los padres igual a este viejo... Le dijo a mi papá que tomará la decisión: si crecía como mestiza él nunca regresaría a la casa. Fue un golpe tremendo para mis padres, pero inmediatamente después de la conversación, a la tarde, me pusieron mi ropa de india. (Rauber, 1992, pág. 32)

Los elementos descritos en los testimonios de las dirigentes indígenas y expresadas fielmente por Rauber, dejan claro que los elementos que identifican a un individuo están más allá de la superficie, más allá del tipo de vestimenta. Existe una negociación interna, un rechazo o aceptación que se refleja o exterioriza.

En Nicaragua estos casos no son aislados. Existe una negociación interna desde hace 500 años, en las que a las personas se le ha enseñado como deben vestirse y negar su cultura, aunque en sus prácticas, costumbre y composición, siguen manifestándolas. De acuerdo a las realidades campesinas de Nicaragua, y el caso de los pueblos del Pacífico Centro, y Norte de Nicaragua caso concreto de la comunidad indígena de la Virgen de Hato, de El Viejo, Chinandega, las familias se encuentran en una composición estructural de características indígenas, estos grupos se identifican y reconocen por sus apellidos.
Cuando se charla con ellos hacen referencia quienes fueron sus antepasados, quienes fueron los primeros pobladores, o bien, los que coincidieron con ellos cuando se establecieron en su lugar (Andino, 1999).

La autoconciencia étnica, pervive en las prácticas y las acciones cotidianas de las población del Hato, aunque tienen un sincretismo religioso es visible la manifestación y arraigo ancestral los cuales son de descendencia Chorotega, cuyas tierras se encuentran custodiadas por una directiva indígena que respalda su sentido de pertenencia por títulos de propiedad comunal.

Las costumbres y actividades culturales se conservan como evidencia del apego ancestral, teniendo una identidad cultural que se interioriza en diferentes niveles de acuerdo al auto conciencia étnica.

\section{Reflexiones conclusivas}

La antropología nicaragüense tiene la responsabilidad de reconstruir desde las manifestaciones actuales en busca del encuentro con los pueblos originarios, continuar con una lectura retrospectiva con base a los componentes culturales que incursionan en la identidad, tomando de referencia los testimonios y las diferentes manifestaciones en búsqueda del trasfondo étnico que se presenta a través de la cultura espiritual y material de las poblaciones.

La auto identificación como pueblos originarios, se evidencia en prácticas cotidianas que se comprenden a partir de elementos ancestrales, articulan el sentido de pertenencia, en relación a las prácticas y saberes ancestrales, así como las tradiciones, costumbres, las formas de organización, la vida comunitaria, la transmisión de generación en generación de los valores espirituales resguardados en las prácticas tradicionales de las poblaciones, vinculando con la cultura material y espiritual.

La reflexión queda enunciada sobre la búsqueda de los elementos originarios que manifiestan las familias, tomando de referencia las manifestaciones de las expresiones que se manifiestan en las costumbres y tradiciones de la población. 


\section{Bibliografía}

Andino, E. M. (1999). Elementos de la antropología para el estudio de la economía nicaraguense: estrategias económicas domésticas. Tesis de maestría. Managua: UNAN-Managua.

Andino, E. M. (2016). Identidad estratégica para el desarrollo comunitario en poblaciones rurales transfronteriza. Tesis de Doctorado. Managua: UNAN-Managua.

APRODIN. (2012). iNosotros si existimos! La lucha de los Pueblos Indígenas del Pacífico, Centro y Norte de Nicaragua por su autodeterminación. Managua: Cooperación Austriaca para el Desarrollo (ADA).

Batalla, G. B. (1990). México profundo: una civilización negada. México : Grijalbo .

Grimson, A. (2011). Los límites de la cultura. Crítica de las teorías de la identidad. Buenos Aires : Siglo XXI.

Guanche, J. (1983). Procesos etnoculturales de Cuba . La Habana: Editorial Letras Cubanas.
Idiáquez, M. M. (1998). La estructura de las comunidades étnicas. Itinerario de una investigación teórica en Nicaragua. Managua: Envío.

Lacayo, A. D. (2007). Nicaragua una reinterpretación. El insconsciente colectivo. Managua: Aldila.

Organización Internacional del Trabajo (OIT). (1989). C169 - Convenio sobre pueblos indígenas y tribales, 1989 (núm. 169). Ginebra : OIT.

Rauber, I. (1992). Hijas del Sol. Habana: Letra Viva.

Ruiz, M. L. (2013). Guillermo Bonfil Batalla. Aportaciones al pensamiento social contemporáneo. Cuicuilco, 115-136.

Salamanca, D. (2012). Los dos rostros indígenas de Nicaragua y Centroamérica. Wani, 6-23.

UICN, URACCAN, \& APRODIN. (2016). Pueblos originarios y afrodescendientes de Nicaragua: etnografía, ecosistemas naturales y áreas protegidas. Managua: IBIS-GESCCA.

\section{Dra. Elvira Maritza Andino}

Universidad Nacional Autónoma de Nicaragua.UNAN-Managua. Facultad de Humanidades y Ciencias Jurídicas Departamento de Antropología, Nicaragua

Alumna Ayudante en la Escuela de Ciencias Sociales de la UNAN, Managua (1984). Encargada de Cátedra de Ciencias Sociales en la Escuela Militar Carlos Fonseca Amador, Isla de la Juventud, Cuba (1985-1987). Licenciada en Ciencias de la Educación con mención en Ciencias Sociales, UNAN-Managua (1987). Docente titular de la Facultad de Humanidades y Ciencias Jurídicas de la UNAN-Managua. Fundadora del Departamento de Antropología (1991) y de la carrera de Antropología Social (1994). Estudios de especialización en Metodología de la Investigación Científica, UNAN-Managua (1992). Máster en Antropología-Etnología, UNAN-Managua (1999). Doctorado en Ciencias Sociales con mención en Gerencia, por la Universidad del Zulia República Bolivariana de Venezuela (2011-2016). Actualmente es Directora del Departamento de Antropología, UNAN- Managua (segundo periodo: 2016-2020). Su tesis doctoral, bajo el tema Identidad estratégica para el desarrollo comunitario, en poblaciones rurales transfronterizas, ha sido inspirada en la experiencia de trabajo de campo de más de dos décadas con poblaciones rurales. En el ámbito del desarrollo comunitario, a partir de los años noventa, ha venido acompañando a más de 30 investigaciones estudiantiles y ha realizado varios estudios en el área de Occidente de Nicaragua, comprometida por sus orígenes con el Cacique Agateyte, de El Viejo, Chinandega. Mujer con liderazgo estudiantil, institucional, familiar. Creadora del Museo Familiar Vladimir Andino In Memoriam(2016). Actualmente Directora del Departamento de Antropología 